\title{
Bone transport versus acute shortening for the management of infected tibial bone defects: a meta-analysis
}

\author{
Hongjie Wen ${ }^{1}$, Shouyan Zhu², Canzhang $\mathrm{Li}^{1}$ and Yongqing $\mathrm{Xu}^{3^{*}}$
}

\begin{abstract}
Background: The treatment for infected tibial bone defects can be a great challenge for the orthopaedic surgeon. This meta-analysis was conducted to compare the safety and efficacy between bone transport (BT) and the acute shortening technique (AST) in the treatment of infected tibial bone defects.

Methods: A literature survey was conducted by searching the PubMed, Web of Science, Cochrane Library, and Embase databases together with the China National Knowledge Infrastructure (CNKI) and the Wanfang database for articles published up to 9 August 2019. The modified Newcastle-Ottawa scale (NOS) was adapted to evaluate the bias and risks in each eligible study. The data of the external fixation index (EFI), bone grafting, bone and functional results, complications, bone union time and characteristics of participants were extracted. RevMan v.5.3 was used to perform relevant statistical analyses. Standard mean difference (SMD) was used for continuous variables and relative risk (RR) for the binary variables. All of the variables included its 95\% confidence interval (Cl).

Results: Five studies, including a total of 199 patients, were included in the study. Statistical significance was observed in the EFI (SMD $=0.63,95 \% \mathrm{Cl}: 0.25,1.01, P=0.001)$ and bone grafting (RR=0.26, 95\%Cl: $0.15,0.46, P<0.00001)$; however, no significance was observed in bone union time ( $S M D=-0.02,95 \% \mathrm{Cl}:-0.39,0.35, P=0.92)$, bone results ( $R R=0.97,95 \% \mathrm{Cl}$ : $0.91,1.04, P=0.41$ ), functional results ( $\mathrm{RR}=0.96,95 \% \mathrm{Cl}: 0.86,1.08, P=0.50$ ) and complications ( $\mathrm{RR}=0.76,95 \% \mathrm{Cl}: 0.41,1.39$, $P=0.37)$.

Conclusions: AST is preferred from the aspect of minimising the treatment period, whereas BT is superior to AST for reducing bone grafting. Due to the limited number of trials, the meaning of this conclusion should be taken with caution for infected tibial bone defects.
\end{abstract}

Keywords: llizarov technique, Tibial, Bone defects, Bone transport, Acute shortening

\section{Introduction}

The treatment for infected tibial bone defects can be a great challenge for the orthopaedic surgeon. The occurrence and progression of infectious bone defects of the tibia are often associated with severe wound infection, soft-tissue defects, vascular and nerve injuries, and joint dysfunction, rendering treatment difficult [1-6]. Most studies [1, 2, 7-9] recommend the Ilizarov technique to repair tibial bone defects because it has several advantages. First, infection can be strictly controlled. Second,

\footnotetext{
* Correspondence: whj20000@163.com

${ }^{3}$ Department of Orthopaedic Surgery, 920th Hospital of Joint Logistics

Support Force, NO. 212 Daguan Road, Xi Shan District, Kunming City 650021,

Yunnan Province, China

Full list of author information is available at the end of the article
}

this technique can tackle varying degrees of bone defects and restore a limb's discrepancy to a satisfactory length. Third, bone defects and soft-tissue defects can be repaired at the same time. Fourth, it eliminates the necessity of bone grafts and donor site morbidity. The main treatment methods include BT and AST, and both methods have their advantages and disadvantages $[6$, $10-14]$. It is still unclear which choice is better.

Currently, there are numerous comparative studies of these two techniques, but no meta-analysis on this topic has been published. The aim of the present metaanalysis was to compare BT and AST for the treatment of infected tibial bone defects and provide some useful

(c) The Author(s). 2020 Open Access This article is distributed under the terms of the Creative Commons Attribution 4.0 International License (http://creativecommons.org/licenses/by/4.0/), which permits unrestricted use, distribution, and 
suggestions for orthopaedic surgeons when facing such disease.

\section{Methods}

\section{Meta-analysis principles}

No ethical approval was required because we performed all the analyses based on previous studies. The present meta-analysis strictly followed the principles of the Preferred Reporting Items for Systematic Reviews and Meta-Analyses (PRISMA) statement [15]. It was prospectively registered in the PROSPERO registry (CRD42019133659).

\section{Search strategy}

The following databases were searched by two individual investigators (WHJ and ZSY): the PubMed, EMBASE, Cochrane, Web of Science Library and Chinese databases, including the Wanfang database and the CNKI. Each database was searched up to 8 August 2019, with language restricted to English and Chinese. We performed the comprehensive literature search by applying the keywords of 'bone transport', 'bone transportation', 'Distraction osteogenesis', 'ilizarov technique', 'acute compression and distraction', 'acute shortening', 'bone defects', 'non-unions', 'tibial'. Detailed search terms are provided in additional file 1.

\section{Study selection}

The inclusion criteria were defined as follows:

(i) open tibial fractures with tibial bone and soft-tissue defects;

(ii) randomised controlled trial (RCT), retrospective or prospective trials;

(iii) age $\geq 16$ years old;

(iv) managements were either bone transport or acute shortening/lengthening with Ilizarov circular external fixator;

(v) the data of eligible patient was complete.

Exclusion criteria were defined as follows:

(i) reviews, case reports, meta-analyses, editorial articles or letters;

(ii) duplicates of previously published papers;

(iii) studies that included children $(<16$ years old).

\section{Data extraction}

A standardised protocol based on comprehensive literature search was designed to extract eligible articles. The following outcome variables were extracted for pooled analysis: external fixation index, bone grafting, heal time, functional results, bone results and number of complications. In one study the external fixation index was reported in days $/ \mathrm{cm}$, which was converted to months/ $\mathrm{cm}$. Moreover, the relevant information of eligible articles was extracted: the first author, country, year of publication, total number, study design, bone defects, and journal reference.

\section{Quality assessment}

Quality assessment of each enrolled study was evaluated by SYZ, CZL and HJW based on a modified version (nine-star scoring system) of the Newcastle-Ottawa Scale (NOS) for retrospective studies [16]. Studies with NOS scores above or equal to the median were considered high quality (low risk of bias).

\section{Statistical analysis}

Two individual investigators applied Review Manager Software (version 5.3; Nordic Cochrane Centre, Copenhagen, Denmark) to conduct statistical analysis and produce

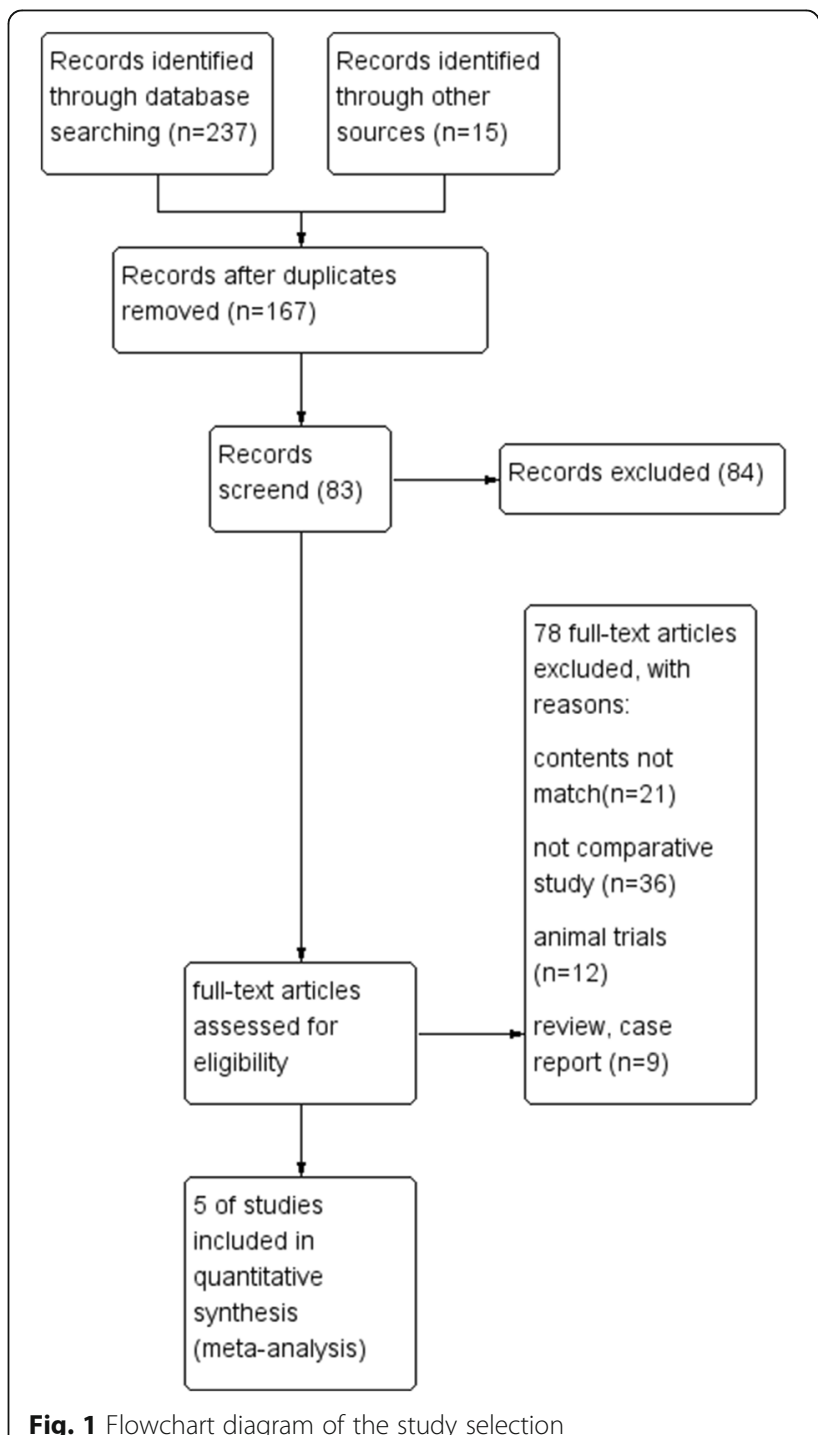


Table 1 Characteristics of the eligible controlled trials

\begin{tabular}{lllllllll}
\hline First author & Year & Country & Study & \multicolumn{2}{l}{ Cases } & \multirow{2}{*}{ NOS } \\
\cline { 5 - 6 } \cline { 5 - 6 } & & & design & BT & AST & \\
\hline Wu [14] & 2017 & China & retrospective & 28 & 22 & 8 \\
Kevin [13] & 2017 & Australia & retrospective & 21 & 21 & 8 \\
Levent [10] & 2016 & Turkey & retrospective & 29 & 45 & 7 \\
Yin [12] & 2014 & China & retrospective & 18 & 13 & 6 \\
Mahaluxmivala [6] & 2005 & UK & retrospective & 6 & 6 & 6 \\
\hline
\end{tabular}

BT Bone transport, AST Acute shortening technique, NOS Newcastle-Ottawa scale

relevant plots. Standard mean difference (SMD) was used for continuous variables and Relative risk (RR) for the binary variables. The $95 \%$ confidence interval $(\mathrm{CI})$ of each variable was calculated and presented. Statistical heterogeneity among studies was analysed $\left(\mathrm{I}^{2}<50 \%, P>0.01\right.$ is the test standard of heterogeneity.). The random-effects model was applied when the heterogeneity between subgroups was high $\left(\mathrm{I}^{2}>50 \%, P<0.05\right)$; otherwise, the fixed-effects model was used. The $P$ value was regarded as the standard to choose the processing model when the $\mathrm{I}^{2}$ value was inconsistent with the $\mathrm{P}$ value, When $P<0.05$, difference was identified statistically significant.

\section{Results}

\section{Included literature}

Concerning the study characteristics; a flow diagram showed the search procedure and the result was summarized in Fig. 1. A total of 252 related articles were searched, and 154 studies were excluded due to the title and abstract. Then, 78 articles were excluded from the 83 studies according to the inclusion criteria. Finally, five retrospective studies [6, 10, 12-14], including 199 patients, were included in the present study. In order to avoid heterogeneity, studies that only applied bone transport or acute shortening were excluded. In the meta-analysis, bone transport was set as the study group and AST as the control group. Tables 1 and 2 summarized the baseline characteristics of the eligible studies and patients.

Quality assessment of the included studies by using NOS for retrospective studies was presented in Table 3.
The median score of NOS was seven. Therefore, among the five studies, three were considered of high methodological quality (low risk of bias); they scored $\geq 7[10,13$, $14]$, whereas the other two studies [6,12], which scored $<7$, were therefore considered of low methodological quality (high risk of bias).

\section{Results of the meta-analysis Bone union time}

In total, three studies $[6,10,12]$ recorded bone union time, and no statistically significant heterogeneity was detected $\left(P=0.18, \mathrm{I}^{2}=42 \%\right)$, so the fixed-effects model was applied and the analysis results displayed that there is no statistically significant difference between control and study group $(\mathrm{SMD}=-0.02,95 \% \mathrm{CI}:-0.39,0.35$, $P=0.92$ ). The results indicated that there is no difference in bone union time between two groups (Fig. 2).

EFI

A total of three studies $[6,10,12]$ reported an EFI, and no statistically significant heterogeneity was detected $\left(P=0.65, \mathrm{I}^{2}=0 \%\right)$. The fixed-effects model was applied to analysis the data and significant difference between the two groups was detected from the result $(\mathrm{SMD}=$ $0.63,95 \%$ CI: $0.25,1.01, P=0.001$ ). The results showed that the EFI of the AST group is lower than that of the BT group (Fig. 3).

\section{Bone grafting}

Overall, four studies $[6,10,12,14]$ recorded the bone grafting rate, and no statistically significant heterogeneity was detected $\left(P=0.76, \mathrm{I}^{2}=0 \%\right)$. The fixed-effects model was applied and significant difference between bone and AST group was detected from the result ( $R R=0.26,95 \%$ CI: $0.15,0.46, P<0.00001)$. The results displayed that the bone grafting rate of AST group is higher than that of the BT group (Fig. 4).

\section{Bone results}

A total of five studies $[6,10,12-14]$ recorded the bone results, and no statistically significant heterogeneity was detected $\left(P=0.91, \mathrm{I}^{2}=0 \%\right)$. The fixed-effects model was

Table 2 Baseline characteristics of the included patients

\begin{tabular}{|c|c|c|c|c|c|c|c|c|}
\hline \multirow[t]{2}{*}{ First author, year } & \multicolumn{2}{|c|}{$\begin{array}{l}\text { Bone defect }(\mathrm{cm}) \text { Mean } \\
\text { value with ranges }\end{array}$} & \multicolumn{2}{|c|}{$\begin{array}{l}\text { Follow-up (months) } \\
\text { Mean value with ranges }\end{array}$} & \multicolumn{2}{|c|}{ Gender (male/total) } & \multicolumn{2}{|c|}{ Age (years Mean value with ranges } \\
\hline & $\overline{\mathrm{AST}}$ & BT & $\overline{\text { AST }}$ & BT & $\overline{\mathrm{AST}}$ & BT & $\overline{\text { AST }}$ & BT \\
\hline Wu, 2017 [14] & $6.7(4.8-11.0)$ & $6.4(4.3-10.0)$ & $40.8(30-66)$ & $40.8(30-66)$ & $12 / 17$ & $15 / 23$ & $39.3(18-65)$ & $38.8(16-67)$ \\
\hline Kevin, 2017 [13] & $5.8(3-10)$ & $7.0(3-10)$ & $20(12-43)$ & $31(12-84)$ & $18 / 21$ & $18 / 21$ & $39.2(20-76)$ & $38.2(18-66)$ \\
\hline Levent, 2016 [10] & $5.9(1-12)$ & $5.3(1-17)$ & $55.6(12-66)$ & $63(36-85)$ & $38 / 45$ & $20 / 29$ & $34.8(17-62)$ & $37.6(15-61)$ \\
\hline Yin, 2014 [12] & $6.3(4.5-9.0)$ & $6.7(4-11)$ & $28.8(16.8-54.5)$ & $28.8(16.8-54.5)$ & $11 / 18$ & $8 / 13$ & $39.3(18-65)$ & $38.8(16-67)$ \\
\hline Mahaluxmivala, 2005 [6] & $4.6(3-6)$ & $5.9(3-7.5)$ & $>18^{\mathrm{a}}$ & $>18^{\mathrm{a}}$ & $6 / 6$ & $5 / 6$ & $36.5(26-54)$ & $39.2(28-52)$ \\
\hline
\end{tabular}

BT Bone transport, AST Acute shortening technique; ${ }^{a}$ values are over certain age 
Table 3 Risk-of-bias assessment of the included studies, according to the modified Newcastle-Ottawa Scale (NOS)

\begin{tabular}{|c|c|c|c|c|c|}
\hline NOS items / Study ID & Wu 2017 & Kevin 2017 & Levent 2016 & Yin 2014 & Mahaluxmivala 2005 \\
\hline Is the case definition adequate? & $\star$ & $\star$ & $\star$ & $\star$ & $\star$ \\
\hline Representativeness of the cases & $\star$ & $\bullet$ & $\star$ & $\bullet$ & $\star$ \\
\hline Selection of controls & $\bullet$ & $\star$ & $\bullet$ & $\bullet$ & $\bullet$ \\
\hline Definition of controls & $\star$ & $\star$ & $\star$ & $\star$ & $\star$ \\
\hline Study controls for the most important factor (i.e., age) & $\star$ & $\star$ & $\bullet$ & $\star$ & $\bullet$ \\
\hline Study controls for the second important factor (i.e., sex) & $\star$ & $\star$ & $\star$ & $\star$ & $\bullet$ \\
\hline Was the measurement method described? & $\star$ & $\star$ & $\star$ & $\star$ & $\star$ \\
\hline Were the methods of measurements similar for cases and controls? & $\star$ & $\star$ & $\star$ & $\star$ & $\star$ \\
\hline Non-response rate & $\star$ & $\star$ & $\star$ & $\bullet$ & $\star$ \\
\hline Total Score & 8 & 8 & 7 & 6 & 6 \\
\hline
\end{tabular}

$\star$ was awarded when the respective information was available

- was awarded if the respective information was unavailable

applied and no statistically significant difference between the two groups was found ( $\mathrm{RR}=0.97,95 \% \mathrm{CI}$ : $0.91,1.04$, $P=0.41$ ). Therefore, statistical results displayed that there is no difference in bone union rate between control and study group (Fig. 5).

\section{Functional results}

In total, five studies $[6,10,12-14]$ described the functional results, and no statistically significant heterogeneity was detected $\left(P=0.89, \mathrm{I}^{2}=0 \%\right)$. The fixed-effects model was applied and the results displayed no significant difference between control and study groups ( $R R=0.96,95 \% \mathrm{CI}$ : $0.86,1.08, P=0.50$ ), indicating bone transport group was no better than AST group in functional results (Fig. 6).

\section{Complication}

Complications were mentioned in three studies [12-14] and had statistically significant heterogeneity $(P=0.004$, $\left.\mathrm{I}^{2}=82 \%\right)$. We performed pooled analysis by randomeffects model and the results displayed that there was no statistically significant difference between the control and study group ( $\mathrm{RR}=0.76,95 \% \mathrm{CI}$ : $0.41,1.39, P=0.37)$, indicating bone transport group was no better than AST group in functional results (Fig. 7).

\section{Publication bias}

A funnel plot according to bone results was produced to display whether there was publication bias. The result showed that the two sides of the funnel plot are roughly symmetrical, indicating low publication bias (Fig. 8). However, the number of included trials $<10$, so the conclusion may not be completely accurate.

\section{Discussion}

Advantages and disadvantages of AST and BT from previous literature

Currently, Ilizarov reconstructions, the Masquelet technique, vascularised and non-vascularised bone grafts and bone substitutes are the main methods to treat tibia defects $[2,8,9,17-22]$. However, bone transfer is the preferred technique for the treatment of infected tibial bone defects $[1,4,23,24]$. Ilizarov reconstruction techniques include two main clinical treatment protocols: bone transport and acute shortening and gradual lengthening $[11,25]$. Bone transport is a safe and reliable approach of tackling segmental tibia bone defect. It can simultaneously repair bone defect and soft-tissue defect. It has the advantages of quick wound healing, shortened treatment duration, less bone grafting and reliable treatment efficacy [26, 27]. However, postoperative complications are common, such as bone exposure and bone non-

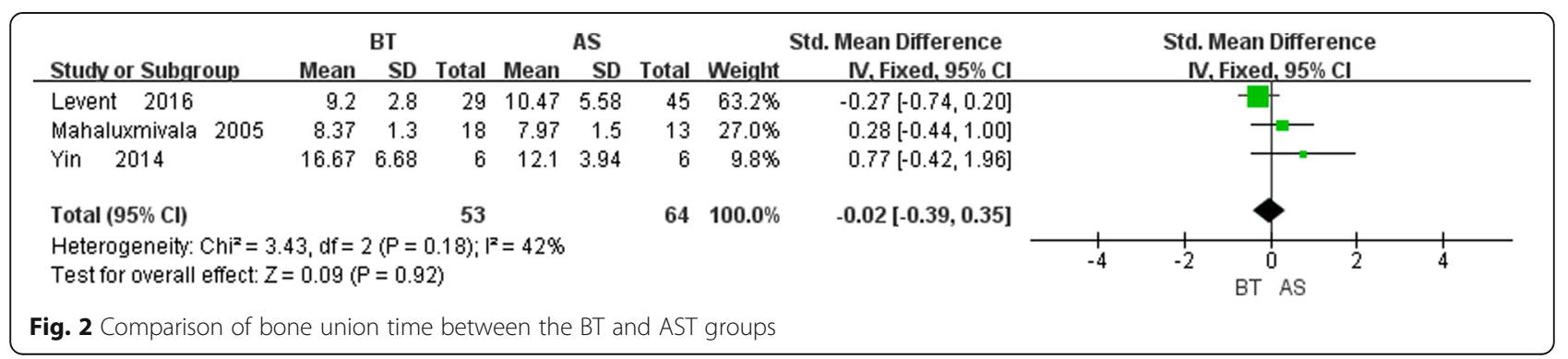




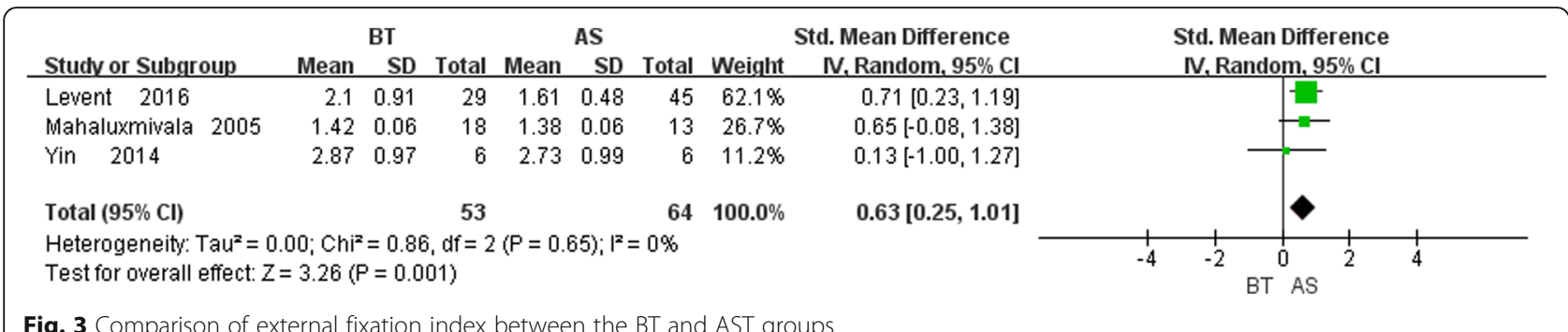

Fig. 3 Comparison of external fixation index between the BT and AST groups

union usually along with axis deviation in long segmental bone transport, consolidation of newly formed bone is poor, delayed union or non-union can occur at the docking site, and pin track infection and screw loosening, stiffness of the knee and ankle joint foot drop can occur [5]. Many studies of the ASD technique have shown that it has obvious advantages and can significantly shorten the time of union [24, 28-30]. It reduces or closes the wound, effectively reduces the soft-tissue tension, and reduces the incidence of postoperative bone infection, bone exposure, osteonecrosis and soft-tissue necrosis; it is especially suitable for patients with large wounds [31-37]. However, according to two studies [38, 39], it may cause vascular and nerve injury and require more bone grafts and a limited shortening distance. At present, there are many comparative studies on bone transport and acute shortening technique in the treatment of infected tibial bone defects, but no conclusion has been reached. As far as the author knows, the present study is the first meta-analysis about the issue.

\section{Outcome analysis}

EFI

The present meta-analysis showed that AST was superior to BT from the aspect of the EFI, which is an effective index to evaluate the treatment of bone defect and non-union with the Ilizarov technique, which is closely related to age, pathological characteristics, osteotomy position, elongation speed and bone defect length [40, 41]. Many studies reported that the EFI of the bone transport group ranged from 0.87 to 2.8 months $/ \mathrm{cm}$ [4,
$5,23,42]$ compared to $1.2-2.5$ months/ $\mathrm{cm}$ in the acute shortening group [24, 30, 32, 33, 35, 36, 39, 43]. In the present study, significant difference was detected in the two groups in terms of the EFI $(P<0.05)$ (Fig. 4), which means the EFI of the BT group was higher than that of the AST group. This result indicated the advantage of the AST group in treatment duration, which is consistent with the current mainstream literature.

\section{Bone union time}

A bone defect area is always filled with soft tissue just because bone ends cannot reach the docking site in time, which may consequently affect bone union time. The AS technique can bring forward and solve the problem of non-union because it shortens the duration of bone defect ends' contact and performs bone grafting at an early stage [12]. Kemal et al. reported on a study of 24 patients with mean defects of $7.01 \mathrm{~cm}$. They reported an average bone union time of $275.5 \pm 70.6$ days [5]. A study of 31 cases reported the mean time to union as 40.1 weeks (12.6-80.7 weeks) [32]. The mean healing index in another study was 30 days/cm [33]. MP Magadum et al. described the mean lengthening achieved as $10 \mathrm{~cm}$, and mean union time was 6.3 months in a study of 27 patients with infected non-union and large bone defects in the tibia [30]. In the meta-analysis, no difference was detected in the two groups, according bone union time $(P>0.01)$. Some studies show that multiplelevel bone transport can significantly decrease bone union time [44]. Results may also be affected by the different bone transport modalities used in the included

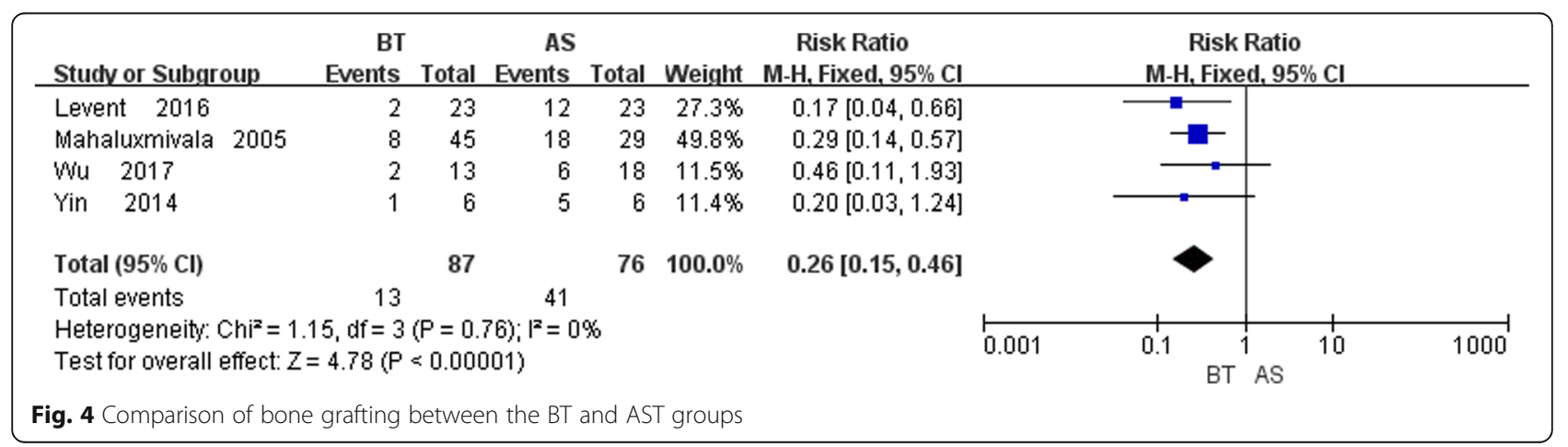




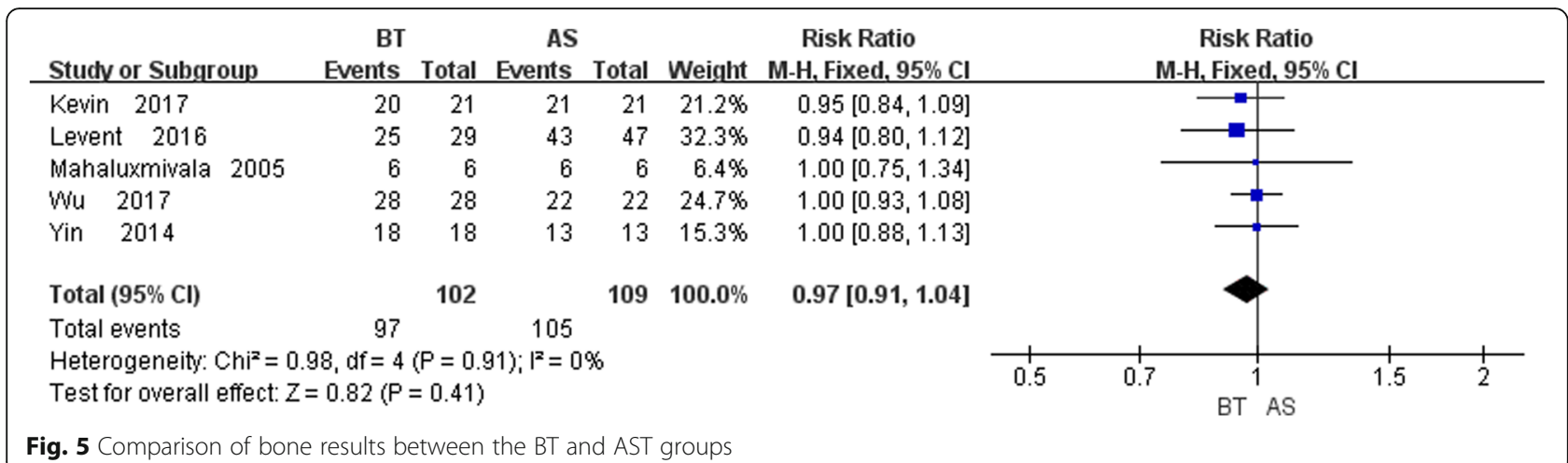

studies. Some studies believe that docking site union is the key factor that affects the whole therapeutic time, and the AS technique is more advantageous in shortening the docking site union time [24, 28-30]. Therefore, the bone union time of the AS group may be shorter. However, bone union may be affected by many factors, such as the severity of the original injury and infection, the length of bone defect and other factors. In addition, the number of studies included was small, so the results should be critically considered.

\section{Bone grafting}

Four studies included in this study reported the bone grafting data, and the results showed that the difference between the two groups was statistically significant $(P<$ 0.05), which means the AST group needed more bone grafting. At present, most of the research claims to perform bone grafting at the docking site to reduce the bone union time [25]. According to previous literature reports, the bone grafting rate of the $\mathrm{BT}$ group ranged from 14.3 to $40 \%$ [1, 23, 45] compared to $20-43 \%$ in the AST group, which is consistent with the present study $[2,11,36]$.

\section{Bone and functional results}

All the eligible trials applied the Association for the Study and Application of the Method of Ilizarov (ASAMI) criteria to assess bone and functional results
[30]. An excellent rate range from 64 to $83 \%$ in the BT group was documented, $[4,19]$ compared to $53-100 \%$ in the AST group [30, 34-36]. Kemal et al. reported bone union of $95.8 \%$ and $12(50 \%)$ cases had excellent radiological results [5]. No difference was detected in the two groups, according to bone results $(P>0.01)$. This suggested that both groups were at the same risk for delayed union, malunion and non-union. Due to the limited number of references, there may be some bias in the results, so it is necessary to include more highquality literature for further analysis and evaluation to draw a more accurate conclusion. All five eligible studies described the detail of functional results, and the result showed that a significant difference was found in the two groups $(P>0.01)$. Studies illustrated that excellent functional results ranged from 38 to $58 \%[4,5,19]$ in the BT group compared to $60-86 \%[30,35,36]$ in the AST group. The functional results mainly depended on professional guidance of functional exercise, prevention of needle penetration too close to the joint, adoption of methods to correct the existing ankle deformity and so on. Although AS has the advantage of earlier wound closure and avoiding a flap graft, the shortened tendon becomes relaxed and prone to foot drop [12].

\section{Complications}

Pin track infection and screw loosening are the most common complications in external fixation, and usually

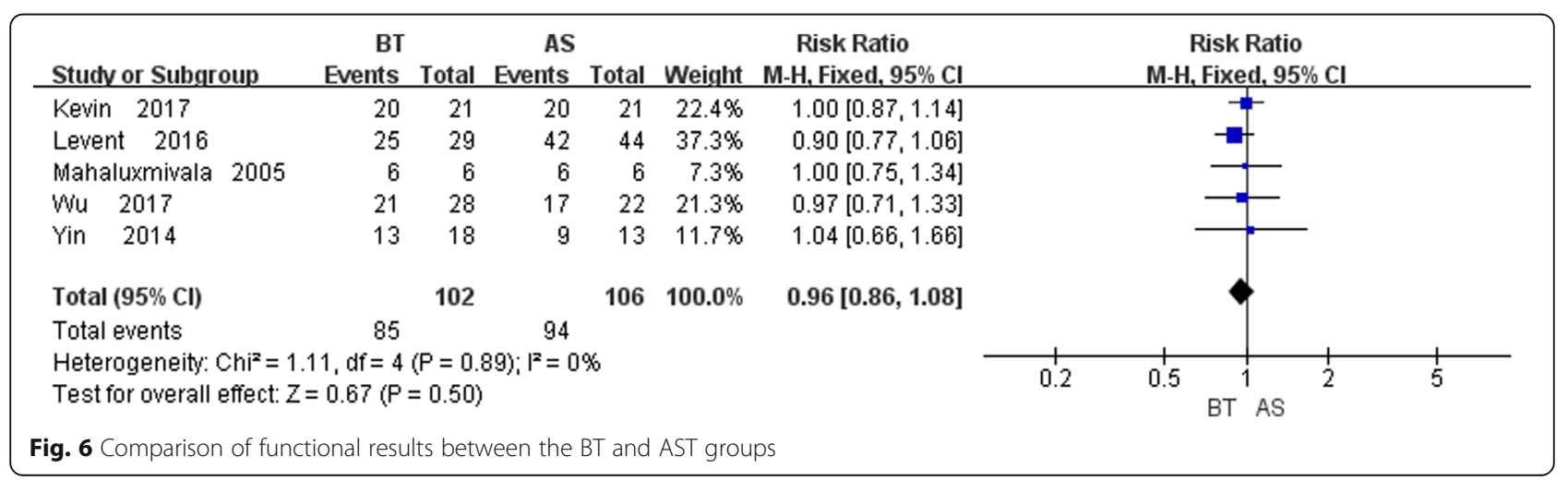




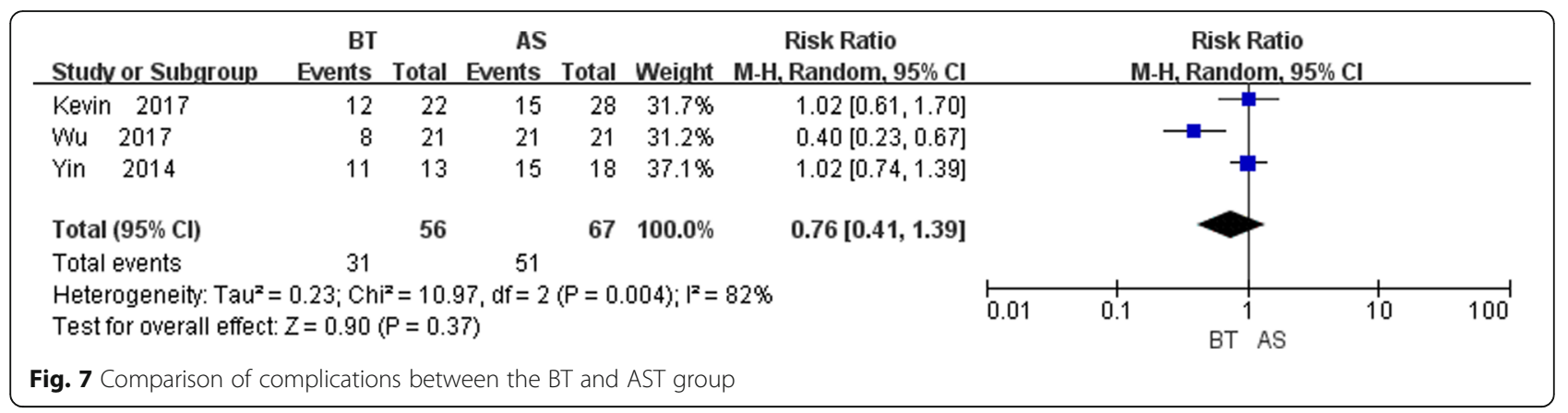

the final results will not be affected by these complications. In terms of reports, limb length discrepancy, permanent nerve and vascular damage, vascular crisis, refracture and newly formed bone infection are rare, and thorough debridement is the key step to controlling bone infection [4]. Studies reported that complications in the BT group ranged from 8.3 to $100 \%[1,4,23,42]$ and 9 to $100 \%$ in the AST group [32, 33, 36, 37, 43]. Sarah et al. recommended the use of Doppler ultrasonography to assess distal pulses as necessary and to choose the appropriate shortening method according to the soft-tissue and wound condition [38]. Three studies published the data about complications, and one significant difference was found in the two groups according to the complications $(P>0.01)$. Because the included studies did not describe the types and detailed statistical data of the complications, this study could not carry out subgroup analysis, so there may be some bias in the results.

\section{Strengths and limitations}

To the best of our knowledge, this is the first metaanalysis to compare the safety and efficacy between bone transport and AST for the treatment of infected tibial bone defects. Moreover, low heterogeneity analysis and publication bias was detected in the meta-analysis. There were certain limitations in the present study. First, all of the eligible studies were retrospective studies, and the sample size was small; most studies were performed in a single centre, which may lead to a certain degree of bias. Therefore, part of the conclusions should be treated with caution. Second, the results may be affected due to the different inclusion and exclusion criteria and measurement indicators of each study. Third, the included literature lacked standardised and unified standards for the recording of variables, especially the external fixation index and bone union time, which resulted in many variables could not be combined for analysis. Fourth, in the five studies, further fixation after removal of external fixation was different, including nail, plate and plaster. The shortening methods were also disparate; immediate shortening or gradual shortening were applied in different studies, and the external fixation types included monolateral fixators and ring fixators. All of these selections may induce heterogeneity and impair the reliability of the conclusion. Therefore, further study based on large-size, multi-centre clinical RCTs, which apply

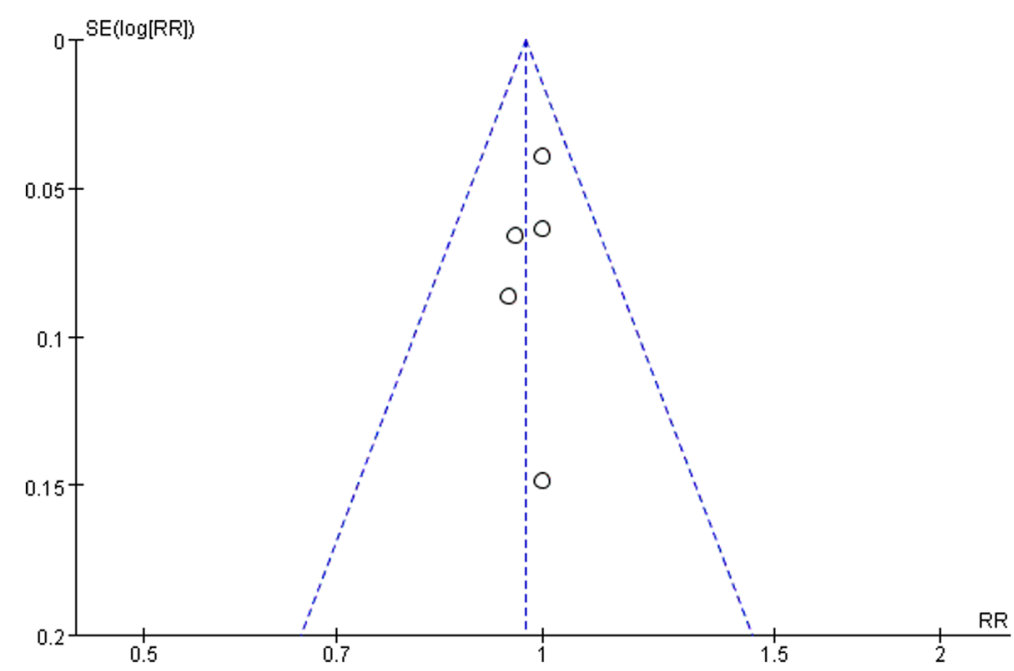

Fig. 8 Funnel plot of the bone results of BT and AST groups. SE, standard error; RR, relative risk 
unified and correct scoring system, evaluation indicators and random methods of blinding, is still necessary in the future for achieving higher-level evidence for clinical treatment.

\section{Conclusions}

AST is preferred from the aspect of minimising the treatment period, but BT is superior to AST for reducing bone grafting. Due to the limited number of trials, the meaning of this conclusion should be taken with caution for infected tibial bone defects.

\section{Supplementary information}

Supplementary information accompanies this paper at https://doi.org/10. 1186/s12891-020-3114-y.

Additional file 1. The search strategies used in the platforms of PubMed and EMBASE.

\section{Abbreviations}

95\% Cl: 95\% confidence interval; AST: Acute shortening technique; BT: Bone transport; CNKI: China National Knowledge Infrastructure; EFI: External fixation index; NOS: Newcastle-Ottawa scale; RR: Relative risk; SMD: Standard mean difference

\section{Acknowledgements}

Not applicable.

\section{Authors' contributions}

HJW participated in the conceptualization and design of this study. HJW, SYZ and CZL conducted the acquisition of data. SYZ and CZL performed the statistical analyses. SYZ was involved in the interpretation of data. HJW drafted the manuscript. YQX revised the manuscript for important intellectual content. All authors have read and approved the manuscript.

\section{Funding}

This study was supported by the National Natural Science Foundation of China: (H0607).

\section{Availability of data and materials}

All data generated or analysed during this study are included in this published article.

\section{Ethics approval and consent to participate}

Not applicable.

\section{Consent for publication}

Not applicable.

\section{Competing interests}

The authors declare that they have no competing interests.

\section{Author details}

${ }^{1}$ Department of Orthopaedic Surgery, The Fourth Affiliated Hospital of Kunming Medical University, Kunming, China. '2Department of Radiology, The Fourth Affiliated Hospital of Kunming Medical University, Kunming, China. ${ }^{3}$ Department of Orthopaedic Surgery, 920th Hospital of Joint Logistics Support Force, NO. 212 Daguan Road, Xi Shan District, Kunming City 650021, Yunnan Province, China.

Received: 2 December 2019 Accepted: 3 February 2020 Published online: 06 February 2020

\section{References}

1. Karargyris O, Polyzois VD, Karabinas P, Mavrogenis AF, Pneumaticos SG. Papineau debridement, llizarov bone transport, and negative-pressure wound closure for septic bone defects of the tibia. Eur J Orthop Surg Traumatol. 2014;24:1013-7.

2. Beltran MJ, Blair JA, Rathbone CR, Hsu JR. The gradual expansion muscle flap. J Orthop Trauma. 2014;28:e15-20.

3. Kovoor CC, George W, Jayakumar R, Guild AJ, Bhaskar D, Cyriac A. Total and subtotal amputation of lower limbs treated by acute shortening, revascularization and early limb lengthening with ilizarov ring fixation - a retrospective study. Injury. 2015;46:1964-8.

4. Yin P, Zhang L, Li T, Zhang L, Wang G, Li J, et al. Infected nonunion of tibia and femur treated by bone transport. J Orthop Surg Res. 2015;10:49.

5. Aktuglu K, Günay H, Alakbarov J. Monofocal bone transport technique for bone defects greater than $5 \mathrm{~cm}$ in tibia: our experience in a case series of 24 patients. Injury. 2016;47:S40-6.

6. Mahaluxmivala J, Nadarajah R, Allen PW, Hill RA. Ilizarov external fixator: acute shortening and lengthening versus bone transport in the management of tibial non-unions. Injury. 2005;36:662-8.

7. Tong K, Zhong Z, Peng Y, Lin C, Cao S, Yang Y, Wang G. Masquelet technique versus llizarov bone transport for reconstruction of lower extremity bone defects following posttraumatic osteomyelitis. Injury. 2017; 48:1616-22.

8. Abdelkhalek M, El-Alfy B, Ali AM. llizarov bone transport versus fibular graft for reconstruction of tibial bone defects in children. J Pediatr Orthop B. 2016;25:556-60.

9. Papakostidis C, Bhandari M, Giannoudis PV. Distraction osteogenesis in the treatment of long bone defects of the lower limbs: effectiveness, complications and clinical results; a systematic review and meta-analysis. Bone Joint J. 2013;95-B:1673-80.

10. Eralp L, Kocaoglu M, Celiktas M, Gülşen M. Is acute compression and distraction superior to segmental bone transport techniques in chronic tibial osteomyelitis ? Comparison of distraction Osteogenesis techniques. Acta Orthop Belg. 2016;82:599-609.

11. Wang $X Y$. Residual limb lengthening using the llizarov technique for the treatment of infectious long bone defect. Orthop J China. 2015;23: 229-34.

12. Yin Q, Sun Z, Gu S, Bao Y, Wei X, Song S. Effectiveness comparison of using bone transport and bone shortening-lengthening for tibial bone and soft tissue defects. Zhongguo Xiu Fu Chong Jian Wai Ke Za Zhi. 2014;31:941-5.

13. Tetsworth K, Paley D, Sen C, Jaffe M, Maar DC, Glatt V, Hohmann E, et al. Bone transport versus acute shortening for the management of infected tibial non-unions with bone defects. Injury. 2017:48:2276-84.

14. Wu Y, Yin Q, Rui Y, Sun Z, Gu S. Ilizarov technique: bone transport versus bone shortening-lengthening for tibial bone and soft-tissue defects. J Orthop Sci. 2017:23:341-5.

15. Shamseer L, Moher D, Clarke M, Ghersi D, Liberati A, Petticrew M, et al. Preferred reporting items for systematic review and meta-analysis protocols (PRISMA-P) 2015: elaboration and explanation. BMJ. 2015;350:g7647.

16. Islam MA, Alam F, Wong KK. Comorbid association of antiphospholipid antibodies and migraine: a systematic review and meta-analysis. Autoimmun Rev. 2017:16(5):512-22.

17. Ashman O, Phillips AM. Treatment of non-unions with bone defects: which option and why? Injury. 2013;44:S43-5.

18. Akcay S, Kazimoglu C. Bone transport of the tibia with a motorized intramedullary lengthening nail:a case report. Acta Orthop. 2014:85:333.

19. Sala F, Thabet AM, Castelli F, Miller AN, Capitani D, Lovisetti G, et al. Bone transport for Postinfectious segmental Tibial bone defects with a combined Ilizarov/Taylor spatial frame technique. J Orthop Trauma. 2011;25:162-8.

20. Nauth A, McKee MD, Einhorn TA, Watson JT, Li R, Schemitsch EH. Managing bone defects. J Orthop Trauma. 2011;25:462-6.

21. El-Gammal TA, Shiha AE, El-Deen MA, El-Sayed A, Kotb MM, Addosooki $\mathrm{Al}$, et al. Management of traumatic tibial defects using free vascularized fibula or llizarov bone transport: a comparative study. Microsurgery. 2008:28:339-46.

22. Sadek AF, Laklok MA, Fouly EH, Elshafie M. Two stage reconstruction versus bone transport in management of resistant infected tibial diaphyseal nonunion with a gap. Arch Orthop Trauma Surg. 2016;136:1233-41.

23. Wang $H$, Wei $X$, Liu $P$, Fu YH, Wang PF, Cong YX, et al. Quality of life and complications at the different stages of bone transport for treatment infected nonunion of the tibia. Medicine (Baltimore). 2017:96:e8569.

24. Guo Z, Shi L, Tian S, Chen W, Lin B. Effectiveness of limbs shortening and re-lengthening in treatment of tibial infectious bone defect and chronic osteomyelitis. Zhongguo Xiu Fu Chong Jian Wai Ke Za Zhi. 2017;31:941-5. 
25. Takahashi M, Kawasaki Y, Matsui Y, Yasui N. Fragmental bone transport in conjunction with acute shortening followed by gradual lengthening for a failed infected nonunion of the tibia. J Orthop Sci. 2010;15:420-4.

26. Guerreschi F, Azzam W, Camagni M, Lovisetti L, Catagni MA. Tetrafocal bone transport of the tibia with circular external fixation a case report. J Bone Joint Suig Am. 2010;92:190-5.

27. Robert Rozbruch S, Weitzman AM, Tracey Watson J, Freudigman P, Katz HV, \|lizarov S. Simultaneous treatment of Tibial bone and soft-tissue defects with the llizarov method. J Orthop Trauma. 2006;20:197-205.

28. Rahal SC, Volpi RS, Vulcano LC. Treatment of segmental Tibial defects using acute bone shortening followed by gradual lengthening with circular external fixator. J Vet Med. 2005;A52:180-5.

29. Zheng ZY, Xue YF. Acute shortening of bone lengthening and marrow transplantation for the treatment of tibial fracture and bone defect. China J Orthop Trauma. 2005;18:689-90.

30. CBY MPM, Phaneesha MS, Ramesh L. Acute compression and lengthening by the llizarov technique for infected nonunion of the tibia with large bone defects. J Orthop Surg. 2006;14:273-9.

31. Sanjun Gu JW, Yongwei W. Experience in the treatment of open long bone defect of tibiofibula with one-stage shortening and two-stage bone lengthening. Chin J Bone Joint Injury. 2014;29:1058-9.

32. Salih S, Mills E, McGregor-Riley J, Dennison M, Royston S. Transverse debridement and acute shortening followed by distraction histogenesis in the treatment of open tibial fractures with bone and soft tissue loss. Strategies Trauma Limb Reconstr. 2018;13:129-35.

33. Lerner A, Fodor L, Soudry M, Peled IJ, Herer D, Ullmann Y. Acute shortening: modular treatment modality for severe combined bone and soft tissue loss of the extremities. J Trauma. 2004:57:603-8.

34. Lavini F, Dall'Oca C, Bartolozzi P. Bone transport and compression-distraction in the treatment of bone loss of the lower limbs. Injury. 2010;41:1191-5.

35. Gulsen M, Ozkan C. Angular shortening and delayed gradual distraction for the treatment of asymmetrical bone and soft tissue defects of tibia: a case series. J Trauma. 2009;66:E61-6.

36. El-Rosasy MA. Acute shortening and re-lengthening in the management of bone and soft-tissue loss in complicated fractures of the tibia. J Bone Joint Surg (Br). 2007;89-B:80-8

37. Parmaksizoglu F, Koprulu AS, Unal MB, Cansu E. Early or delayed limb lengthening after acute shortening in the treatment of traumatic belowknee amputations and Gustilo and Anderson type IIIC open tibial fractures. J Bone Joint Surg (Br). 2010;92-B:1563-7.

38. Pierrie SN, Hsu JR. Shortening and angulation strategies to address composite bone and soft tissue defects. J Orthop Trauma. 2017;31:S32-5.

39. Atbasi Z, Demiralp B, Kilic E, Kose O, Kurklu M, Basbozkurt M. Angiographic evaluation of arterial configuration after acute tibial shortening. Eur J Orthop Surg Traumatol. 2014;24:1587-95.

40. Krappinger D, Irenberger A, Zegg M, Huber B, Huber B. Treatment of large posttraumatic tibial bone defects using the llizarov method: a subjective outcome assessment. Arch Orthop Trauma Surg. 2013;133:789-95.

41. McKee M, Yoo DJ, Zdero R, Dupere M, Wild L, Schemitsch EH, et al. Combined single-stage osseous and soft tissue reconstruction of the tibia with the llizarov method and tissue transfer. J Orthop Trauma. 2008;22:183-9.

42. Oh CW, Song HR, Roh JY, Oh JK, Min WK, Kyung HS, et al. Bone transport over an intramedullary nail for reconstruction of long bone defects in tibia. Arch Orthop Trauma Surg. 2008;128:801-8.

43. Cengiz Sen M. Mehmet Kocaoglu, Levent Eralp, Gulsen M, Cinar M. bifocal compression-distraction in the acute treatment of grade III open tibia fractures with bone and soft-tissue loss a report of 24 cases. J Orthop Trauma. 2004;18:150-7.

44. Zhang Y, Wang Y, Di J, Peng A. Double-level bone transport for large posttraumatic tibial bone defects: a single Centre experience of sixteen cases. Int Orthop. 2018:42:1157-64.

45. Lalit MC, Jashan V, Sudhir K, Kapoor S, Mehtani A, Dhaon BK. The llizarov method in infected nonunion of fractures. Injury, Int J Care Injured. 2000;31: 509-17.

\section{Publisher's Note}

Springer Nature remains neutral with regard to jurisdictional claims in published maps and institutional affiliations.

\section{Ready to submit your research? Choose BMC and benefit from:}

- fast, convenient online submission

- thorough peer review by experienced researchers in your field

- rapid publication on acceptance

- support for research data, including large and complex data types

- gold Open Access which fosters wider collaboration and increased citations

- maximum visibility for your research: over $100 \mathrm{M}$ website views per year

At BMC, research is always in progress.

Learn more biomedcentral.com/submissions 